\title{
MOSQUITO CONTROL TRAINING MANUAL
}

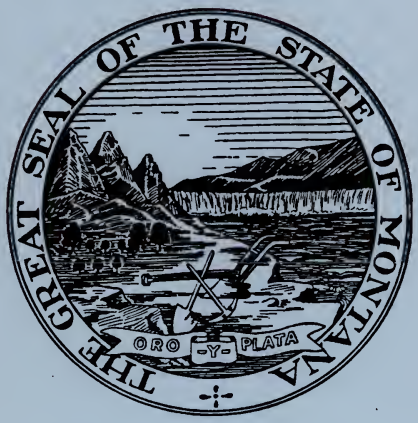

STATE DOCUMENTS COLLECTION

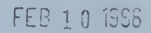

MON' ${ }^{-1}$ AT MTL LIOARBYY

1515 L. 6t AVE.

HLLENA, MON'TANA 59620

MONTANA DEPARTMENT OF HEALTH \& ENVIRONMENTAL SCIENCES FOOD \& CONSUMER SAFETY BUREAU

MONTANA DEPARTMENT OF AGRICULTURE ENVIRONMENTAL MANAGEMENT DIVISION HELENA, MT 59620-0205

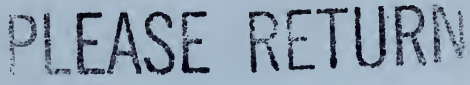


MONTANA STATE LIBRARY
8 632.771 A7mct $1988 ?$ c.1
Mosquito control training manuet

A'S $\div 2008$

quito control training manuat

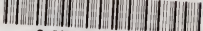

30864000591167

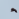




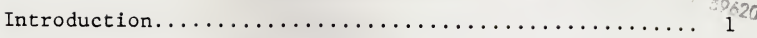

CHAPTER I - Montana Mosquitoes.................... 2

A. Introduction............................ 2

B. Mosquito Life History.................... 2

C. Identification of Mosquitoes.............. 5

D. Notes on Important Mosquito Species.......... 11

CHAPTER II - Classification of Mosquito Production Sources... 17 CHAPTER III - Mosquito Surveys.................... 18

A. Original Basic Survey $\ldots \ldots \ldots \ldots \ldots \ldots \ldots \ldots \ldots \ldots \ldots \ldots \ldots \ldots \ldots$

B. Operation Surveys $\ldots \ldots \ldots \ldots \ldots \ldots \ldots \ldots \ldots \ldots \ldots \ldots \ldots$

CHAPTER IV - Methods of Control..................... 20

A. Physical Control ....................... 20

B. Biological Control.................... 21

C. Chemical Control Methods.................. 23

CHAPTER V - Insecticides for Mosquito Control.......... 26

A. Classification........................ 26

B. Insecticide Formulations ................. 26

C. Criteria for Insecticide Selection and Use.......28

D. Information on Specific Chemicals for Mosquito Control.......................... 30

CHAPTER VI - Equipment for Ground Application........... 35

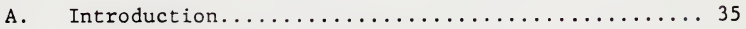

B. Types of Larviciding Equipment............. 35

C. Types of Adulticiding Equipment............ 36

D. Equipment Selection.................... 36 
CHAPTER VII - Chemical Application................... 38

A. Equipment Calibration.................. 38

B. Standardizing Application Rates................ 39

C. Computation of Acreage..................... 39

D. Formulation Dilution................... 41

E. Determining Amount of Mixed Chemical Need....... 42

F. Computation of Dosage Rates............... 42

G. Methods of Varying the Dosage Rates...........43

Appendix................................ 47

Lineal measure conversions................. 47

Square measure conversions................. 47

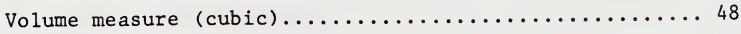

Volume measure (1iquid) $\ldots \ldots \ldots \ldots \ldots \ldots \ldots \ldots \ldots \ldots \ldots$

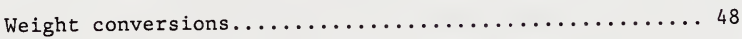

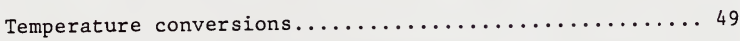

Calculating Capacity of Sprayer Tanks........... 49

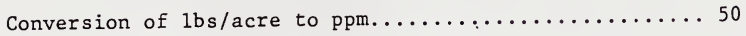




\section{INTRODUCTION}

It is necessary to understand the life cycle and habits of mosquito species in order to effectively and efficiently control mosquito populations. Detailed surveys are essential for developing and implementing an effective integrated mosquito management strategy and for evaluation and improvement of control programs. Survey and evaluation are continuing processes that must accompany control.

Control programs conducted by mosquito control districts organized under state enabling legislation (MCA Title 7, Sections 7-22-2401 through 7-22-2448) have been the most effective in providing a reliable means for reducing pest and disease-bearing mosquito populations to acceptable levels. Districts thus organized have more program continuity, higher levels of financing and a more reliable source of financial support. These advantages make effective integrated mosquito management programs easier to attain.

The vector control specialist of the Montana Department of Health and Environmental Sciences may be contacted for technical advice, information or assistance in forming mosquito control programs and problems. A pesticide applicator's license, obtainable from the Environmental Management Division of the State Department of Agriculture, is required by all commercial and government applicators who supervise the application of pesticides. 



\section{CHAPTER I}

\section{MONTANA MOSQUITOES}

\section{A. Introduction}

Mosquito abatement and other public health personnel in Montana may be called upon to combat the deleterious effects of particular mosquitoes. Knowledge about the breeding habitats and habits of the species involved will assist them in the conduct of their duties.

There have been 45 species of mosquitoes reported in Montana distributed among six genera: Aedes, 30 species; Anopheles, 3 species; Culex, 4 species; Culiseta, 6 species; Coquillettidia, 1 species; and Psorophora, 1 species. The different species do not assume equal importance due to a variety of factors including difference in abundance, distribution, and feeding habits. Some species can act as vectors (spread a disease); some are highly annoying to man and livestock and are of economic importance in Montana.

\section{B. Mosquito Life History}

Mosquitoes have complete metamorphosis. They pass through four distinct developmental stages: from eggs to larvae to pupae to adults. Within this developmental pattern, there are four larval stages (instars) interspersed by molts in which the larvae "shed their skin". The eggs, larvae and pupae require water for development. The aquatic stages can be found in extremely high concentrations -- several million in a single acre of irrigated pasture.

1. The egg stage. Mosquito eggs are spindle-shaped structures that darken soon after laying to resemble specks of soot. Most eggs are less than a sixteenth of an inch long.

The eggs of our region's most common pest mosquitoes, Aedes species, are laid singly on damp soil or among grass roots near water. (One Aedes species lays its eggs above the water line in tree holes or containers.) Aedes are a temporary water mosquito, implying that they are produced in water which is retained on the surface for a minimum of about 7 days but which disappears during the course of the season. They may also be found in permanent or semi-permanent bodies of water which have periodic fluctuations in water levels. Water which has little fluctuation in water level will produce few Aedes. Fluctuating water levels that flood the eggs stimulate hatching, and provide temporary pools of water for development. 
The eggs of these Aedes or temporary water mosquitoes overwinter on the ground. It is not unusual for eggs to withstand five years of recurrent freezing and drying before they are flooded and hatch. Hence, two or three dry years do not solve most mosquito problems. Several years which are successively drier will result in several egg lines below the high water mark. If all egg lines were then flooded, a much larger than normal hatch could occur. of many species must be exposed to successive periods Eggs drying and/or chilling before they can hatch. These mosquito species usually produce only one brood each year. By contrast, the eggs of the most predominant Aedes mosquitoes in this region (see Table I) do not require drying or chilling to hatch and multiple generations within a single season are possible.

The eggs of another important group of mosquitoes are laid either singly (Anopheles species) or in small floating rafts (Culex and Culiseta species) on the surface of more permanent bodies of water. The eggs of these "permanent water mosquitoes" must have water continuously to remain viable. This group includes most of the mosquitoes that transmit diseases. (Particularly important in this group is the species Culex tarsalis which is the principle vector of human and equine encephalitis.) Their eggs cannot survive freezing or drying, and must be laid on more permanent bodies of water. The eggs of these permanent water species hatch two or three days after they are laid. Several generations are produced each summer. All mosquito eggs need to be submerged to hatch into the larval stage.

2. The larval stage. The larval phase of a mosquito's development is the only period of growth in its life. Larvae pass through four instars or stages. They shed their protective skin, the exoskeleton, before progressing to the next instar, and produce a new exoskeleton to accommodate their increased size. Recognition of the instar that larvae are in is of practical importance. More time is available for an operator to larvicide if earlier instars are detected. Less insecticide is required to kill 3 rd instar larvae than 4 th instar larvae.

Larvae usually begin to appear in large numbers when water temperatures reach fifty degrees Fahrenheit. Mosquito larvae can be observed suspended from the water surface by an air tube (through which they breathe) or held horizontally against the surface by float hairs. When they are disturbed, larvae dive using a characteristic jerky movement that gives them their common name: wigglers. Operators should avoid casting a shadow over the area to be sampled since larvae will dive in response to this change in light intensity. The larvae will most often be found near emergent vegetation or floating objects that afford them some protection. 
Larvae feed on small life forms and particles of organic material in the water. The amount of organic material affects the rate of development. However water temperature is the most critical factor in determining the rate of larval development. Under ideal conditions, some species (e.g. Aedes nigromaculis) can pass through the four larval stages in less than a week. Another common species, Culiseta inornata, requires 10-14 days at the same temperatures. If the water persists long enough to allow larvae to develop through the fourth instar, pupae appear.

3. The pupal stage. The pupa emerges through a slit in the fourth instar larval skin. It looks like a dark coma. The nonfeeding pupa is the last aquatic stage in a mosquito's life. It moves through the water in a somersaulting motion and is commonly known as a "tumbler". The mosquito larva is transformed to an adult during the pupal stage. This transformation may require one day to a week or more, depending on the species and ambient temperatures. Development of the four aquatic stages can take place in as little as 5-7 days but more commonly requires 10-21 days.

The pupa is resistant to insecticides because it does not feed and the pupal case is more difficult to penetrate than the larval "skin". However, oils will penetrate their breathing "trumpets" and kili them.

4. The adult stage. When the adult mosquito is fully formed, it emerges from a slit in the pupal skin, crawls onto the water surface and soon is able to fly short distances. The adult begins to disperse in 12-14 hours. This is a good time to adulticide fields from which a hatch has emerged since they are still confined to a relatively small area. Males usually emerge first and remain near the mosquito production sources. Adult female mosquitoes usually don't fly more than a few miles from the water where they developed. Some species (particularly some Aedes species) may travel 20 miles or more; some fly only a few hundred yards. More specific flight range data is contained in descriptions of the major mosquito species.

Adult Aedes mosquitoes are usually most active at dawn and dusk, but many species can readily attack during the day or night. Permanent water mosquitoes of the Culex and Culiseta genera tend to bite most actively at dusk and during darkness.

Only adult female mosquitoes take a blood meal. Males feed on nectar and other plant juices. Females of some species may feed several times during their lifetimes. A few days after taking a blood meal, the adult female mosquito develops eggs that she will lay to begin a new cycle. The protein and other elements gathered through her blood 
feedings are essential to production of a full complement of eggs in most species.

Most mosquitoes are short-lived; the majority live less than one month, yet a significant number will survive one or two months under favorable conditions such as moderately low temperatures and high humidities. Fertilized adult females of some permanent water mosquitoes (Culex and Culiseta species) live through an entire winter by resting in protected areas such as rock piles, rodent borrows, culverts, or outbuildings and can live six months or more.

\section{Identification of Mosquitoes}

Vector Control Bulletin \#1, Montana Mosquitoes, Part I--Identification and Biology (obtainable from the Department of Health and Environmental Sciences) may be consulted for detailed information. The most common mosquitoes are Aedes species. Most control efforts are directed at this group. The other common genera are Culex and Culiseta.

There are a number of reasons for mosquito indentification. These include:

1. Disease prevention programs require that control efforts be directed against those species which are capable of acting as vectors (transmit diseases).

2. Different species develop at different rates. Thus operators may need to control 3 rd instar larvae of one species within one day but may be able to wait several days to control another.

3. Identification of species of adult mosquitoes causing annoyance in a particular area will give the operator a clue to the type and location of larval production sources causing the problem. (Different species tend to prefer different types of water and tend to have different flight ranges.)

4. Species differ in their susceptibility to pesticides. The operator may he able to use lower rates to control some species.

Adult mosquitoes are small two-winged insects belonging to the Order Diptera (Figure 1). The body of an adult mosquito is divided into threc distinct regions: head, thorax and abdomen. The foiluwing features will distinguish mosquitoes from similar insects. An elongated proboscis, a pair of maxillary palpi and a pair of long, many segmented antennae extend forward from the head. The wing veins and margins will have scales. 
The proboscis of the female mosquito is adopted for piercing and sucking blood. The sex of mosquitoes can be distinguished by examining the whorls of hair that cover their antennae. Female mosquitoes have almost bare antennae by comparison to the bushy antennae of the males (Figure 2). The maxillary palpi appearing on either side of the proboscis are as long as the proboscis in males of all Montana genera. The palpi of all females (except Anopheles species) are very short. The Anopheles females, which have long palpi, lack the bushy antennae of the males (Figure 2).

Keys to identify 4 th instar larvae and adult female mosquitoes to genus are included on page 7 . Figures 1-4 illustrate key characteristics. Most structures can be seen with a $10 x$ hand lens. A few will require a microscope magnification of 40 power.

Identification to species is not covered in this manual. Species' descriptions are included with notes on the seven most important and common species in Montana. Adult specimens of these species may be recognized with a hand lens or the unaided eye. A microscope of greater than 40 power may be needed to distinguish the species of some larval specimens.

The table below indicates the most numerous mosquito species in Montana. Data was derived by collection and identification of over 6000 mosquitoes from 33 counties. The species found and abundance of each will vary seasonally and from area to are but most are found throughout the state.

TABLE I

MOSQUITO SPECIES ABUNDANCE

Rank

1
2
3
4
5
6
7
Species

Aedes vexans

Aedes melanimon

Aedes dorsalis

Culex tarsalis

Aedes idahoens is

Aedes nigromaculis

Culiseta inornata

"other species"
$\%$

40.1

21.2

11.3

7.4

4.8

4. 0

3. 0

8.2
Running \%

40.1

61.3

72.6

80.0

84.8

88.8

91.8

100.0 


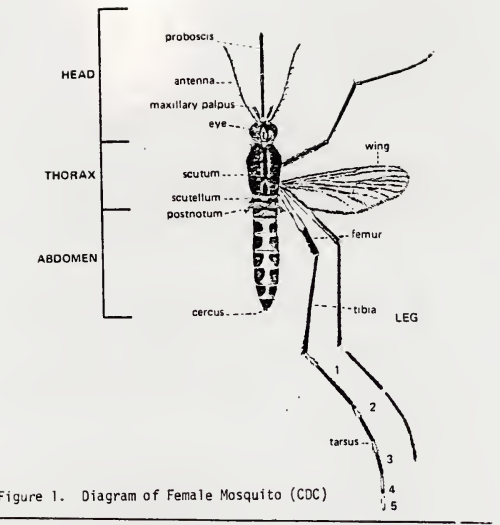

Figure 2. Comparison of Male and Female Mosquitoes

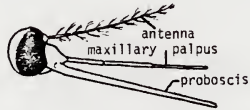

Head of Anopheles female

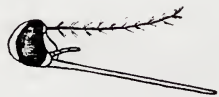

Head of Culex female
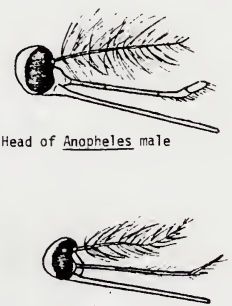

Head of Culex male 


\section{Key to Nontana Genera of Fourth Instar Larvae \\ (note figure 3 illustrating terminal abdominal segments)}

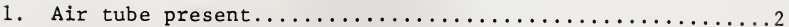

Air tube absent...................................

2. Pecten absent; air tube short, conical, sharply

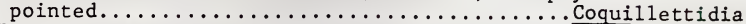
Pecten present; air tube not sharply pointed...........

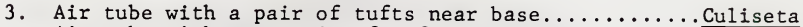
Air tube without a pair of tufts near base.............

4. Air tube with several pairs of tufts or single

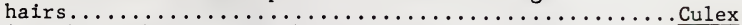
Air tube with not more than one pair of tufts...........

5. Anal segment ringed by sclerotized plate and pierced

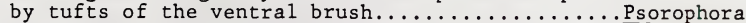
Anal segment not completely ringed by sclerotized

plate, or if ringed, the ventral brush does not

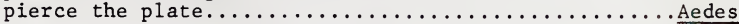

Key to Montana Genera of Adult Female Mosquitoes

1. Palpi about as long as proboscis, scutellum rounded, not lobed (Figures $1 \& 2$ )........................ Palpi much shorter than proboscis; scutellum trilobed (Figures $1 \& 2) \ldots \ldots \ldots \ldots \ldots \ldots \ldots \ldots$

2. Tip of abdomen pointed, segments 7 and 8 narrowed, 8 retractile (Figure 4$) \ldots \ldots \ldots \ldots \ldots \ldots \ldots$ Tip of abdomen blunt, not narrowed, segment

8 short but not retractile (Figure 4$) \ldots \ldots \ldots \ldots \ldots \ldots$

3. First hind tarsal segment with 2 widely

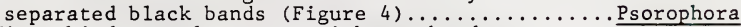
First hind tarsal segment with one band or

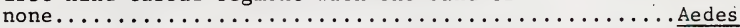

4. Wing scales very broad; mixed dark and light colored; proboscis pale banded (Figures $1 \& 4$ )......... Coquillettidia Wing scales hair-like; proboscis pale banded or

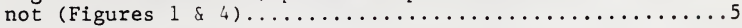

5. Base of subcostal vein without a tuft of hairs on underside of wing; cross-veins on wing

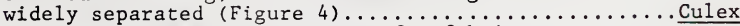
Base of subcostal vein with a tuft of hairs on underside of wing; cross-veins on wing narrowly separated or nearly in line (Figure 4$) \ldots \ldots \ldots$. . . . . . 
Figure 3.

\section{LARVAL CHARACTERS USED IN CLASSIFICATION TO GENUS}

\section{A. EDES}

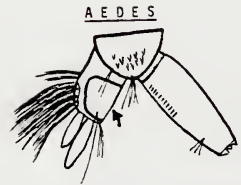

Saddle not ringing anal segment:

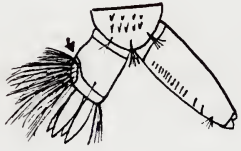

or, if saddle rings anal segment, tufts of ventral brush do not penetrate saddle

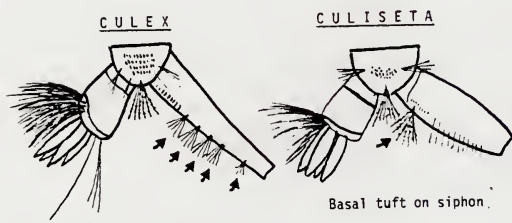

Multiple ventral tufts on siphon

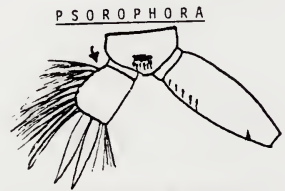

Saddle rings anal segment and is pierced by tufts of ventral brush

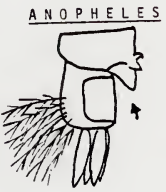

Respiratory siphon abser:

\section{COQUILLETTIDIA}

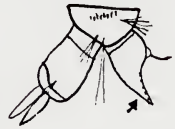

Siphon pointed, hardened; adaotec for penetrating plant stems. 


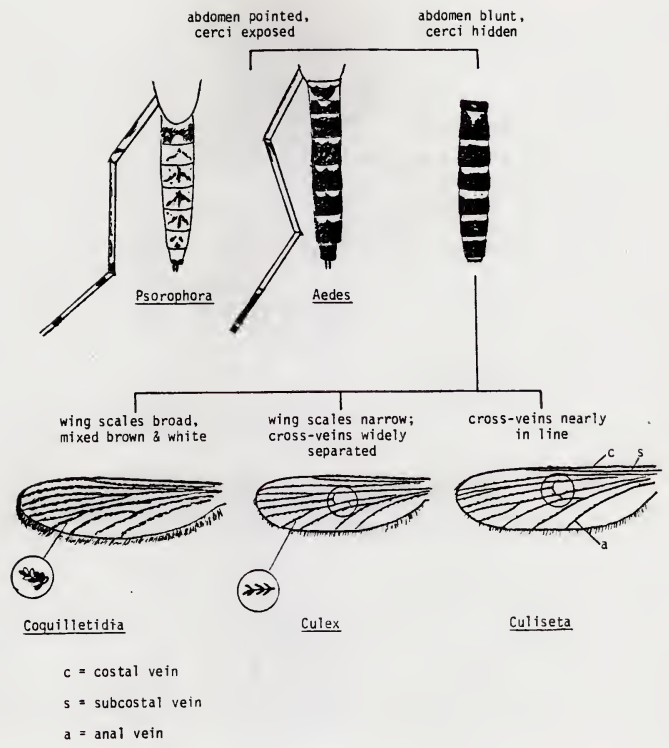

Figure 4. jid;ram nf Characteristics of Mosquito Genera 
D. Notes on Important Mosquito Species

1. Aedes vexans

Description: Aedes vexans, commonly known as the inland floodwater mosquito is a small to medium sized mosquito. The adult is easily recognized by the B-shaped white scale patches on the upper surface of the abdomen and the very narrow white bands on one side of the hind tarsal joints.

Bionomics: Eggs are laid singly on the ground, hatching when flooding occurs. The U.S. Department of Health, Education, and Welfare publication entitled "Mosquitoes of Public Health Importance and their Control" states that over most of their range, Aedes vexans produce several broods each year but that in some western states where flooding occurs only in the spring they are single-brooded. Mail noted that the rate of development of eggs of Aedes vexans was very uneven, hatching occuring at irregular intervals. Hearle observed that not all eggs hatch with a single flooding but that larvae appear periodically after alternate flooding and drying of the eggs during the course of the summer. Development of aquatic stages generally requires 10 to 21 days depending on temperatures. However at water temperatures of 50_F development may take 6 weeks. Eggs of Aedes vexans are very resistant to unfavorable environmental conditions. They have been observed to resist drying for up to 20 months in a refrigerator. Aedes vexans breeds in rain pools, flood water, roadside puddles, and practically all bodies of fresh water. In Montana it is one of the dominant species in irrigated areas. The preferred larval habitat is open sunlit pools such as in roadside ditches and flooded meadows under irrigation. This species is rarely found in shaded situations. Pupae are capable of developing into adults on moist soil in the absence of free water. Adults are strong fliers and commonly migrate 5 to 10 miles from their breeding sites. They are frequently. collected in light traps from May through September. Adults can live nearly two months.

Importance: Aedes vexans ranks among the three most important pest mosquitoes in Montana. It occurs in enormous numbers and is a very aggressive, vicious biter, especially at dusk and after dark. Mammals appear to be their preferred food source.

2. Aedes dorsalis

Description: Adults are medium sized mosquitoes that may be recognized by a combination of the following characters: (1) a longitudinal whitish stripe on the upper surface of the abdomen (note Figure 1); (2) pale bands that overlap the tarsal joints, and; (3) pale scales predominating on the costal and anal veins of the wings. Other microscopic 
characteristics also distinguish them from Aedes melanimon and another species which they resemble.

Bionomics: Eggs are laid singly either on shallow water or in damp depressions. They may remain viable for several years if not flooded. This species overwinters in the egg stage. The larval habitat is quite diverse. It thrives best in waters of high alkalinity but has a $\mathrm{pH}$ tolerance range from about 7.1 to 9.6 . Its preferred habitat appears to be grassy pools exposed to direct sunlight. Larvae commonly develop in irrigation and flood waters. They have been found in open temporary grassy pools, semi-permanent pools with cattails, and other aquatic vegetation as well as in shaded woodland pools. Frequently they are associated with Aedes vexans. At room temperature eggs have been known to hatch in 5 days. In hot weather larvae mature in nature in about 8 days. It is possible to have a new generation every 17 days. Larvae are fairly resistant to drying and pupae can be stranded up to 48 hours without water and still produce adults. Adults have been found from early April until late November, but are most common from May to the first heavy frost in September. Aedes dorsalis is a strong flier and has an effective flight range of 10 to 20 miles or more. Adult females are especially active at dusk, but can also be active on calm cloudy days. A considerable number may also feed at night.

Importance: Aedes dorsalis is one of the three most important mosquito pest species in Montana. This mosquito is an important economic factor on agriculture because of its brief developmental period and the fact that there can be a new generation each time water fills egg containing depressions. Its life cycle is well adapted to the flood system of irrigation. Aedes dorsalis avidly attacks man and livestock making it a severe pest. It occasionally feeds on birds and may be a minor vector of Western equine encephalitis.

\section{Aedes melanimon}

Description: Adult Aedes melanimon strongly resemble Aedes dorsalis, sharing the first two characteristic noted above. However they may usually be distinguished by the costal vein which is predominately dark in A. melanimon.

Bionomics: This species is found in many types of intermittently irrigated or flooded situations. Larvae may be found along the edge of clear mountain streams, snow melt pools, woodland pools and temporary rain ponds but are most commonly found in overflow pools along streams and in irrigation water in shaded or partly shaded situations (as in irrigated pastures and alfalfa fields). Aedes melanimon tolerates high salinity. In very hot weather larvae can develop very rapidly, passing from larvae to adult in less 
than 1 week. Pupae can survive on damp soil. While eggs are laid in damp areas, they are also resistant to drying and may survive several years. They overwinter in the egg stage. Females will bite during daylight hours in shaded situations but are more active at dusk. Adults may be found between late April and September. They may move 10 or more miles from a production source when assisted by prevailing winds.

Importance: At times, this mosquito may be important in Montana as an economic pest of livestock. Studies in Colorado indicated that $92 \%$ of this species collected were engorged with cattle blood. It is among the most abundant species in some mosquito control areas. Aedes melanimon has been found to be naturally infected with Western equine encephalitis virus. It may be important in building up the level of virus in nature through an ancillary cycle involving jackrabbits and birds.

\section{Aedes nigromaculis}

Description: Adult Aedes nigromaculis are medium sized mosquitoes which resemble Aedes dorsalis and Aedes melanimon in having a longitudinal whitish stripe on the upper surface of the abdomen. However the white bands on the tarsal segments occur only on one side (the basal side) of the tarsal joints (Figure 1). The proboscis may or may not have a white ring.

Bionomics: This species overwinters in the egg stage but eggs do not appear to require a cold stimulus for hatching. Aedes nigromaculis is able to produce a new brood with each flooding or irrigation, resulting in many generations and large populations each year. Larvae appear to prefer moderately alkaline conditions and are frequently found in open sunlit pools of irrigation and other temporary water. Larvae have been found in the middle of May. Larvae can grow very rapidly and pupate in 3-4 days. The pupal stage lasts one to two days. Since pupae will survive in damp places, 5 days of warm standing water can produce an emergence of adults. However, at $50 \mathrm{~F}$ the aquatic stages can take two weeks to develop. AdulEs have typically been collected from late April through the end of August, although one collection was recorded at Cascade in mid-November, 1929. THe females usually only live one to three weeks and hence will only lay one or two batches of eggs. The adult female readily feeds during the day but is most active at dusk. Biting is greatly reduced during the evening hours. Thus misting or fogging to control adults of this species may not be as effective during the darkness. This species normally remains near the sites where they were produced but may range 2 to 5 miles, particularly in late summer. 
Importance: Aedes nigromaculis is very important within its range and is a severe pest in irrigation districts. It readily attacks man and animals and inflicts painful bites. Large populations may be produced, resulting in serious economic losses due to annoyance of livestock and

recreationists. Viruses of Western equine, California and St. Louis encephalitis have been associated with this species but it is not thought to be a major vector species.

5. Aedes idahoensis

Description: Adult Aedes idahoensis females are medium sized dark-legged (no tarsal bands) mosquitoes. It may be distinguished from the numerous other dark-legged Aedes species by the coloration of its wing scales. In other species wing scales are dark or pale scaled patches are confined to the bases of the wing veins. Aedes idahoensis specimens will have several wing veins (e. $\bar{g}$. the subcostal vein--See Figure 4) which are predominately pale scaled. This species is regarded as a sub-species of Aedes spencerii by many authors.

Bionomics: Winter is passed in the egg stage. There is one generation per year. Like Aedes dorsalis it prefers alkaline habitats. Eggs may be 1 aid $2-1 / 2$ days after feeding. Mail states that the average number of eggs laid by individuals in the laboratory was 53.1. These eggs were not observed to hatch unless subjected to temperatures below freezing. There is probably only one generation per year. At constant temperatures, the average length of larval life was 13 days at 71 degrees $F$ and 5 days 89 degrees $F$. Larvae may be found in snow or rain pools, open meadows, roadside ditches, etc. Adults may fly several miles from their larval habitats. While it is more active at dusk, it may also be a vicious biter during the day, readily attacking in bright sunlight.

Importance: Aedes idahoensis is one of the most important species in Montana due to its wide distribution and large number in some mosquito control areas. It may be a. serious pest to both man and livestock.

6. Culex tarsalis

Description: Adult Culex tarsalis females are a medium sized brownish mosquito. It is easily recognized by its blunt abdomen, white ring on the proboscis and white bands that overlap the tarsal joints. Larvae will have five pairs of multiple siphonal tufts inserted in a nearly straight line.

Bionomics: Culex tarsalis has several generations per year. Almost any collection of temporary or semi-permanent water (usually waste water) is a suitable larval habitat. Larvae 
are frequently found in water associated with irrigation, for example, canals, ditches, borrow pits, impoundments, ground pools, and hoof prints. Culex tarsalis often breeds in water of high organic content such as effluent from cesspools, dairy barns or corrals, and has a wide range of tolerance to different ions. Eggs are laid as rafts on water, each female generally depositing two rafts. Egg rafts may contain from 50 to 150 eggs. Eggs usually hatch within 2 days. Larvae develop in 5 to 8 days under

favorable conditions and pupae develop in 2 to 3 days. In cool weather the life cycle may take several weeks. Most $C$. tarsalis adults will remain within 1 or 2 miles of the production sources. However, studies indicate that they will fly up to 11 miles. The adult female mainly feeds from dusk to dawn and quietly rests in secluded spots during the day. Usual resting areas are in grasses and shrubs but they are frequently found on shaded sides of buildings, porches, under bridges, and so forth. This species is readily taken in light traps and dry ice (carbon dioxide) traps. Adults have been collected in Montana from mid-April to mid-September. This mosquito overwinters as the engorged mated female. This mosquito occurs in two forms; one requiring a blood meal to produce eggs, the other not requiring blood.

Importance: Culex tarsalis is the most important vector of Western equine encephalitis virus to man and horses in Montana. To date the greatest number of such cases occurred in 1965 with 333 cases reported in horses and 12 in man. Virus activity is detected annually. St. Louis encephalitis, which occurs sporadically in Montana, is also spread by Culex tarsalis. Birds, which act as a reservoir of these diseases, appear to be the preferred host of this species particularly in the spring. However, C. tarsalis appears to switch its feeding preference by mid-season and more readily attacks cattle, horses and man.

WE virus cycle in western U.S.

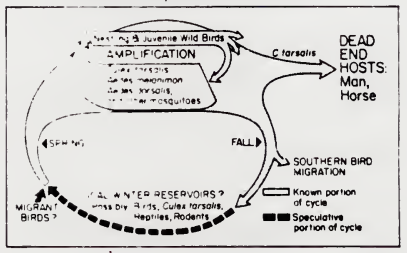




\section{Culiseta inornata}

Description: The adult female Culiseta inornata is a large grayish to light brown mosquito that can be distinguished from others of the Culiseta genus by: (1) the presence of pale scales scattered along the costal vein of the wing and on the hind tarsi 1 and 2 , and (2) the absence of pale scaled bands on the tarsal segments (see Figure 4). They have no conspicuous scale patches on their wings.

Bionomics: This mosquito overwinters as a hibernating adult female in sheltered places. The hibernating female comes out during warm winter days and early in the spring. Breeding occurs throughout the spring and summer. Eggs are laid in boat shaped masses on the water surface. Larvae are frequently found in very cold water. Permanent pools are preferred breeding places although semi-permanent water may also be used. The first generations develop somewhat slowly in the spring due to the low temperatures of most pools, but later in the summer development is much more rapid. Earliest larval collections have been made in Montana on June 3 at an elevation of 7,000 feet. Larvae are common by late June. They can live under a wide variety of conditions having been taken not only from very cold water but, as Mail reported, from warm sulphur water where each instar was coated with a deposit of sulphur. Adults have been commonly collected from June to September. They are often associated with but seem to slightly preceed the appearance of Culex tarsalis. Culiseta inornata are strongly attracted to light. They feed most actively at dusk and may also show a peak in flight activity at dawn. Little flight activity occurs during broad daylight.

Importance: Culiseta inornata does not have a strong blood lust for man but can be troublesome if numerous. Although this species has been found to be naturally infected with Western equine encephalitis virus, its feeding preferences make it unlikely to be an important vector to man. The females show a preference for the blood of large mammals such as livestock. Where large populations exist it may be expected to cause an economic loss to livestock producers. 


\section{CLASSIFICATION OF MOSQUITO PRODUCTION SOURCES}

Not all water produces mosquitoes. Water that stands on the surface at least five or six days, is less than two feet deep, and is slow or stagnant may produce mosquitoes. Water that is less than six inches deep and contains emergent vegetation is especially productive mosquito habitat. Mosquito larvae will not develop in deep, open water exposed to wave action or in streams that flow rapidiy. Ponds which have straight abrupt banks and little emergent vegetation and running water usually produce few mosquitoes. As indicated earlier, water with little fluctuation in levels produces few Aedes species.

Mosquito breeding places may be classed as temporary, permanent or semi-permanent. Temporary breeding pools remain for a limited period of time following each flooding. Permanent water remains throughout the year. Semi-permanent water areas remain throughout most o.r all of a mosquito season following an initial flooding.

Mosquito breeding places may also be classified as to their location. They may be classified as "on field" (including surface pools, irrigation laterals and drains) or "off field" (including road side ditches, or borrow pits, wasteland areas, abandoned canals and laterals, drainage ditches, natural waterways, oxbows, sloughs and distribution systems). Over 95 per cent of the total breeding area was associated with "on field" mosquito breeding places in one irrigated area studied in Montana. These accounted for over 70 per cent of all mosquito production during the entire season. Thus in most areas suffering from severe mosquito infestations, more than 90 per cent of all mosquito production may be associated with the use of water for irrigation. In non-irrigated areas, snow melt pools, spring run-off into low areas or depressions and a rising water table account for a higher percentage of the mosquitoes produced.

Mosquito larvae of some species will also develop in small containers such as watering troughs, tires and tree holes. 


\section{MOSQUITO SURVEYS}

Two types of surveys are widely used: the original basic survey
and the operational survey.

\section{A. Original Basic Survey}

The original basic survey determines the species of mosquitoes, their source, location and seasonal density. Mosquito control maps are used for orientation and locating larval production sources and adult sampling stations. To promote a sound mosquito management program, surveys should include recording information on individual production sites when making the original basic the water sources, times and frequencreage estimates, origin of the sources and any unique frequency of flooding, permanence of source. This information is of value for to a production seasonal breeding acreage that would for estimating the expected (as opposed to the amount of acreage that to be treated each year and for estimating the types of control that can produce mosquitoes) most effectively, the number of personnel needed that may be used equipment and amount and type of inonnel needed, type of control agent.

\section{B. Operational Surveys}

The operational survey is a continuing evaluation of the mosquito control program and is extremely valuable in daily operations. efficiency, the times that iarvae refines information on control significance of each larval soure appear in each source, and the indexes. Such surveys det source according to the production general fluctuations rather than determining index (showing of mosquitoes present). Operational surveys the actual numbers adult mosquito surveys .

1. Larval surveys. In conducting larval surveys, a dipper water surface near inches in diameter is scooped through the water surface near emergent vegetation. Aedes larvae are collected by a rapid skimming movement of the dipper with one side depressed below the water surface, ending the stroke just as the dipper is filled. Where clumps of Anopheles vegetation are present, it is easiest to collect vegetation into the for collection of Culicine larvae (Aedestion is required and Psorophora) than for collections of An Aulex, $\frac{\text { Culiseta }}{\text { larvae }}$ surface when disturbed larva are more likely to dive below the of dips made and the num shadows or movement. The number order to calculate a breeding index. The breeding index may 
be defined as the number of larvae per square foot of water surface. Therefore, the number of larvae collected divided by the number of times that 4 dips are taken equals the breeding index ( $B I=$ \# larvae $\times 4$ - \#dips). Unless the mosquito production source is very large, a mosquito breeding index of less than 1 is not normally controlled. One can determine the relative importance of each breeding site or station by calculating the production index (breeding index $x$ the area $=$ production index of the site or station). Both pre-treatment and post-treatment larval counts should be made. Pretreatment surveys ensure proper timing of applications and minimize the amount of area treated. Pretreatment and post-treatment larval surveys will also help evaluate control efficiency and determine which production sources are most important.

2. Adult Surveys. Adult surveys may be light trap collections, biting collections, resting collections, or carbon dioxide or baited trap collections. Adult mosquito surveys provide information on (1) the species present, (2) mosquito population densities in different areas, (3) the effectiveness of the control efforts throughout the season and (4) a means of evaluating the effectiveness of specific treatments. Adult light trap collections depend upon a phototropic response. Mosquito species differ in their response to light; some being attracted readily, others poorly. After being attracted to the light; a fan is usually employed to blow the mosquitoes into a bag or killing jar. Biting collections are carried out by capturing the adult female mosquito with an aspirator as she attempts to obtain a blood meal from a host. When making population estimates with the bite count method, a predetermined time period is established. The count per given period that will be tolerated by residents in an area varies from region to region and must be determined for each area. Biting and light trap collections are the most common forms of adult surveys. Resting station collections are made by aspirating the adults which remain inactive during the day, resting in cool, humid places. Resting stations may be such sites as stables, chicken houses, culverts, and so forth. Egg samples or egg-sod surveys are not typically made in Montana but have been employed in large districts in other states. 


\section{METHODS OF CONTROL}

Integrated mosquito management or integrated control, as used here, means the selection and use of the most suitable techniques and methods in a compatible manner. Mosquito management techniques fall into three general categories: (1) physical control, also known as water management or source reduction; biological control; and (3) chemical control.

The basic philosophy of integrated mosquito management is that no single mosquito control method will be entirely successful or appropriate in all instances. Integrated mosquito management is aimed at reducing mosquito populations while minimizing the environmental impact and health risks of the control activity itself.

A second basic philosophy for mosquito control is that only by treatment of cause (larval mosquito habitat) rather than effect (mosquito populations) can a problem become less severe. For this reason, since mosquitoes require shallow standing water for development, physical control methods are generally the preferred approaches in mosquito control. As a practical matter, the use of chemicals will be required for the temporary suppression of mosquito populations. Chemical control should assume less importance as physical and biological control programs develop. Although physical control, biological control and chemical control have been integrated for many years, mosquito control managers must make a conscientious effort to integrate the mosquito control technologies that are available.

\section{A. Physical Control}

Physical control involves altering mosquito larval habitat in ways that discourage survival. Physical control is accomplished by the removal of free, shallow, standing water contributing to mosquito production or by the elimination of harborage present within the water. Source reduction or permanent control may involve diking, ditching, draining, dredging, deepening, filling or water level management.

In agricultural areas, practicing proper irrigation techniques and carefully constructing irrigation projects, will reduce mosquito populations. Mosquito producing sites around impoundments can be minimized by clearing vegetation during construction, by eliminating long, shallow irregular shorelines, by making borrow (ditches) and low areas draining and by controlling water leveis. Larval habitat created by irrigation water can be avoided or eliminated if main canals and laterals are built in tight soils or are adequately lined, if drains are installed to prevent ponding and if distribution systems are cleaned and well maintained. Adequate drainage and return flow systems should be installed to remove waste water from all 
irrigated fields. Mosquito breeding on flood irrigated fields can be minimized through land levelling or grading. Irrigation water can be managed more intensively and waste water reduced by converting to sprinkler systems although adult mosquitoes may still be attracted to these areas.

When waterfowl development projects are within the mosquito flight range of communities or recreational sites, improved water management of the refuge will alleviate mosquito problems. Waterfowl areas that are flooded during the mosquito season should be diked or constructed with steep shorelines to preclude shallow areas. Water depths of two feet or more should be maintained and fluctuations in the water level should be minimized.

Physical control may be integrated with biological control by e.g. the construction of a system of ditches in a marsh to allow greater access of predators (such as fish) to mosquito larvae. Deepening parts of the temporary pools of water may also create semi-permanent ponds and permit fish to survive and control larvae that appear with later flooding during the season.

\section{B. Biological Control}

Biological control is a valuable component of an integrated control program. Biological control is the use of natural enemies, whether they are introduced or otherwise manipulated to control mosquito pests. Few insects have as many natural enemies as the mosquito. A number of these natural enemies are being tested as control agents. They include flatworms, mucilaginous seeds, backswimmers, hydra, roundworms, bacteria and fish. Today, however, the practice of biological control is essentially limited to the use of fish that feed on aquatic mosquito stages, and the use of bacterial preparations.

The biological control concept has been very popular since it reduces pesticide usage, minimizes direct toxic effects to non-target organisms, reduces mosquito populations that are resistant to insecticides, and is accepted by many 1 and owners that object to the use of conventional pesticides.

1. Use of mosquitofish.

The livebearing mosquitofish, Gambusia affinis, has been very effective in controlling mosquitoes in more permanent bodies of water throughout Montana. Mosquitofish are trapped or netted from the thermal ponds early each spring and are transferred in buckets to other ponds, marshes or sloughs where mosquito larvae are known to develop.

Experience has shown that planting mosquitofish at 300 to 400 per acre early in the spring can eliminate two to four chemical applications throughout the summer. Since the availability of mosquitofish may be limited, sensitive sites such as swimming areas used by children, water hazards on 
golf courses and wetlands with high fish and wildlife value, are often treated with priority. Mosquitofish may be used effectively in deep water swamps or those with dense emergent vegetation where hand labor cannot function effectively, if at all, in applying chemical pesticides.

For the most effective use of mosquitofish, a mosquito control program should have facilities for rearing, holding and distribution. Rearing is most economical and practical under natural conditions since the young will be eaten by the older fish. Conveniently located ponds which are of a size and depth to facilitate the capture of the fish are desirable. A portion of the shoreline must be accessible and the water clear of vegetation to permit use of seines and scoop nets. A scoop net consisting of a hoop at ached to a 6-8 foot pole and covered with window screen has proved most useful. Regular feeding during the early spring will sometimes permit the fish to mature earlier than normal and thereby increase the number of fish available for distribution. Since Gambusia do not reproduce during the winter season, the establishment of many rearing ponds is desirable to assure a sufficient supply. Since they are not adapted to harsh winter conditions, they die as water temperatures drop. Permanent populations of Gambusia are therefore restricted to warm winter ponds and streams. In these waters mosquitofish overwinter naturally and can be used economically.

Only simple equipment is needed for transporting Gambusia. A number of small containers are preferred to a large tank. Three to five gallon plastic containers, with lids are best. Water from the rearing pond or dechlorinated tap water may be used for transportation. Before releasing the fish, water from the new location should be added gradually to avoid the shock of a sudden change in water temperature. When transportation time is likely to be more than eight hours or in hot weather, containers should be covered and kept shaded/cool, the number of fish/bucket should be reduced and higher quality water (such as dechlorinated tap water) should be used. Mortality also appears to be reduced if $\mathrm{fish}$ are not fed for 24 hours prior to transportation.

2. Use of Bacillus thuringiensis israelensis (BTI).

BTI is a spore forming bacterium that produces a toxic protein crystal under specific conditions. When mosquito larvae consume the crystal their gut lining is disrupted and the larvae die. Only feeding larvae are affected; adults, pupae and late 4 th instar larvae are not controlled. Because of this, and since the BTI crystal has a short residual ( $1-3$ days), timing of applications is very critical. BTI is effective against the predominate mosquitoes in Montana and is very selective; non-target species such as bees and natural predators of mosquito 
larvae (such as backswimmers) are not affected. The EPA has recently registered several formulations. The flowable formulation (Teknar) is applied by conventional liquid insecticide application equipment at one pint per acre, while the wettable powder Bactimos is applied at 2 oz/acre. Abbott will also have formulations available in the near future.

\section{Chemical Control Methods}

Three general approaches to chemical control are commonly used in mosquito management programs. They include (1) larviciding, pre-larviciding or prehatch treatment and (3) adulticiding. Pre-treatment surveys should be taken prior to any chemical application. This will help to ensure that: (1) only mosquito production sources or areas meriting treatment are controlled; (2) the most appropriate type and formulation of insecticide is selected; and (3) applications will be properly timed. Chemical control practices should be compatible with other mosquito management activities. Successfully integrating pesticides into a program also involves selecting the proper insecticide and applying the minimum effective rate to appropriate sites. (These factors are further discussed in the section on insecticides for mosquito control.)

1. Larviciding. Larviciding involves introducing an insecticide directly into the aquatic source that contains significant numbers of mosquito larvae. Larviciding is generally the preferred chemical control approach since smaller amounts of insecticide are used to treat smaller areas, killing larger numbers of mosquitoes over a longer period of time. This approach tends to limit the amount of area treated (and amount of insecticide used) to the greatest degree. Larviciding has been conducted by application of fuel oil plus spreader, highly refined oils, insecticide granules, emulsifiable concentrates or solutions to a body of water. The choice of approach and chemical depends upon a number of variables discussed in the section on mosquito control chemicals.

2. Pre-larviciding (Pre-hatch Treatments). Pre-hatch treatments consist of applying approved insecticide granules on low areas that collect rainfall, annual run-off or seepage or to the ice of snow melt pools before the larval stages actually appear. Identifying and precisely outlining these areas depends upon experiences, accurate surveys and records. Areas to be treated by pre-larviciding must be carefuliy selected to insure that the insecticide will not be flushed from the area and contaminate potable water supplies or water containing valuable non-target resources. The main advantages of this approach stem from savings in application costs since application can be made more rapidly when an area is free of mud and water. In addition, areas may be too extensive to enable an applicator to make 
applications in a timely fashion if he waits until water and larvae are present. The disadvantages are that: (1) larger than necessary areas may be treated if less than the expected amount of flooding occurs and (2) greater than expected flooding may result in flushing of insecticide from an area or concentrations of an insecticide may be too low to effectively control larvae.

3. Adulticiding. Adulticiding or the control of adult mosquitoes is the third type of chemical control commonly used in an integrated mosquito management program. Adult mosquito surveys which accompany adulticiding indicate the intensity of the mosquito problem, the effectiveness of the overall program from year to year and the need to intensify other integrated management activities. When adult mosquito numbers obtained from local surveys reach predetermined levels, adulticiding should be undertaken. Action levels will vary from one community to another. Controlling adult mosquitoes may involve spraying surfaces where mosquitoes rest in large numbers. More often, space spraying is conducted between dusk and dawn when most mosquitoes are active and direct contact between the insecticide and adult mosquito is more likely.

Adulticiding is conducted through the use of thermal fogging, misting or ultra-low-volume (ULV) equipment. Adulticiding is the most difficult form of mosquito control to practice in terms of applying the correct dosage and obtaining the proper coverage that is necessary for efficient control.

The effectiveness of each adulticiding application varies with climatic conditions. Under ideal conditions, the wind does not exceed five miles per hour, there is a temperature of 65 degrees $F$ to 75 degrees $F$, and the relative humidity is 60 to 80 per cent. ULV application of malathion should not be made if the temperature exceeds 82 degrees $F$. Space spraying is conducted as near as possible at right angles to the wind. Low wind currents are depended upon to disperse the insecticide over the 300 to 400 foot swath width which may result under favorable conditions with thermal fog or ultra low volume applications.

Ultra-low volume or ULV applications have largely replaced thermal fogging and misting because less insecticide is used, thermal decomposition of insecticide does not occur, diesel fuel pollution and traffic hazards are eliminated and better spray characteristics can be obtained. However since pure or concentrated insecticide is dispensed, chemical and equipment use directions must be followed rigorously and the performance of the machine must be continually assessed to assure that accidents do not occur. The hazard of spotting of automobile paint increases with droplet size. 
Misting machines disseminate a wide array of different sized particles. This may result in wastage of some chemical but enables applicators to use the machine during daylight hours and under more adverse wind and temperature conditions. Misters can be used for short term residual mosquito control in parks and in bushes and trees in rural or urban residential areas. Under these conditions the mist is directed at lower angle than the customary angle of 45 degrees above the horizontal that is used when space spraying. If vegetation is tall, the mist should be directed at the upper part of it. The vehicle speed should be $5 \mathrm{mph}$ or less when treating low sparse vegetation and 3 mph or less when vegetation is dense. In the latter case or under hot, dry conditions, the effective swath width may not exceed 100 feet. Under more ideal conditions, it may be 200 feet.

Disadvantages of adult mosquito control are: 1) There is less control over non-target organism exposure, 2) More insecticide is used per mosquito killed, 3) The effect is more temporary than it is with other forms of mosquito control, and 4) A repellent effect may occur. Routine adulticiding or adulticiding only on the basis of telephone complaints can be a useless and expensive procedure.

Nonetheless, adulticiding can be a valuable supplement to other forms of mosquito control.

Large numbers of adult mosquitoes around production sites may be treated using space sprays to prevent dispersal or migration into nearby communities. It is more commonly used to control adult mosquitoes that have invaded a community. Adult mosquito control is practiced preferentially only when disease outbreaks threaten public health. 


\section{INSECTICIDES FOR MOSQUITO CONTROL}

\section{A. Classification}

Mosquito control pesticides may be classified according to their method of use, origin or mode of action.

1. Use classification. An insecticide used to kill mosquito larvae is called a larvicide. Similarly, insecticides lethal to pupae may be called pupicides and those effective against adults are called adulticides. Some larvicides also control pupae and adults, e.g. Flit MLO kills larvae and pupae and may kill adults which come to lay eggs on the water surface. Similarly some larvicides will have a direct toxic effect on adults through space application or residual on vegetation.

2. Origin classification. Mosquito control insecticides fall into three major groups of chemical compounds: inorganic, natural organic and synthetic organic. Those currently used are primarily natural organic compounds (e.g. oils and botanicals) or the synthetic organic compounds which include organophosphates (e.g. malathion, fenthion, chlorpyrifos), carbamates (e.g. Baygon, Sevin), insect growth regulators (e.g. Altosid) or synthetic pyrethroids (e.g. Resmethrin).

3. Mode of action classification. A common method of classifying insecticides is based on means by which the chemical enters the insect. Thus, stomach poisons are ingested and absorbed through the alimentary system; contact poisons penetrate the body wall; and respiratory poisons enter the insect through their breathing apparatus.

\section{B. Insecticide Formulations}

Insecticides are formulated to simplify application, control application quantities and to increase effectiveness and safety. They are available in two categories: liquid formulations and dry formulations.

1. Liquid formulations. Liquid formulations may be solutions, emulsions or flowable, water-dispersible powders. These formulations are popular since they are usually the most convenient and economical to use. Solutions include special "larviciding" oils used as is to control larvae or pupae and concentrated adulticides for use in ULV operations. An emulsion is a suspension of droplets of one fluid in another with which it cannot normally mix. This is made possible with the help of special emulsifier compounds. Compared with solutions, emulsions are less bulky, need less solvents, are cheaper and present less transportation and 
application difficulties. They are usually more effective than similar solution or water dispersible powder formulations. The advantages of concentrates are considerable, but a concentrated, highly-potent insecticide is hazardous to handle, proper equipment must be provided, and the handler must be fully trained in correct safety procedures. Participation in an occupational preventative health program such as periodic testing of blood to detect subclinical poisoning by organophosphates is recommended.

2. Dry formulations. The solid formulation larvicides are usually a combination or mixture of insecticides with an inert carrier in the form of dusts, briquettes or granules. Capsules or "tossits" may also be included here. They may consist of a toxic liquid center (such as pyrethrum) encapsulated in an outer shell which dissolves when submerged in water. Similarly "microencapsulation" is a technique in which the droplets of insecticide are covered with a thin layer of water soluble polymer. This formulation is seldom used in mosquito control but may become more important in the future.

(a) Dust formulations. Dust formulations are subject to drift and do not penetrate emergent vegetation well enough to serve as an effective larvicide. In addition to the potential hazards to the environment from drift, the application of toxic dusts may also involve hazards to the operators. This formulation has a higher toxicity to bees than other formulations and is not used for mosquito control in Montana.

(b) Granular formulations. Granular formulations are not effective against pupae or adult mosquitoes. Since it is important to obtain a quick kill so larvae cannot reach the pupal stage, a major portion of the toxicant must be released from granules within a 24 hour period. Most granules will release 80-100 per cent of the toxicant within 24-48 hours. However, formulations prepared with highly volatile solvents have a slower speed of release after storage of 10-21 weeks. Thus, in hot weather where larval development is rapid and fourth instar larvae are present, release may (on occasion) be too slow for effective control.

Two types of granular formulations are available for different uses: coated sand core granules and the sorptive or impregnated types (e.g. those with a bentonite core). The coated sand core granules are heavier, safer to handle and produce a better distribution pattern. They also penetrate more easily through vegetation due to their heavier weight. The sorptive or impregnated types are lighter and give better dispersion. They are suitable for low-volume, high-concentrate formulations. They are inferior to 
sand-coated granules in penetration and distribution properties because of their light weight.

Granular formulations have a number of advantages over liquid and dust formulations. They: (1) penetrate emergent vegetation better, (2) give better distribution and more accurate coverage, (3) cause a minimum residue problem on food and forage crops, (4) are relatively safer for operations, (5) are highly effective as pre-hatch

treatments, (6) increase speed of application in some situations and (7) they only require inexpensive equipment. The principal disadvantage is high cost. Dry formulations of toxicants are generally twice as expensive as liquid larvicides.

C. Criteria for Insecticide Selection and Use

1. Select and apply pesticides in accordance with federal and state laws, regulations, and label instructions. A variety of insecticides are registered for mosquito control. Since registrations are periodically reviewed and certain restrictions may be imposed, applicators in doubt should consult with the State Department of Agriculture and State Department of Health and Environmental Sciences prior to using them.

2. Select and use pesticides to complement physical or biological control methods. For example, the selective applications of a larvicide non-toxic to the fish might be indicated in a source which is heavily populated by mosquito larvae and has inadequate numbers of fish, in the source, to give satisfactory control or if inadequate numbers of fish are available for planting.

3. Apply pesticides selectively to the proper life stage of the mosquito. Insecticides may be most effective against; early stages of larvae, lates stages of larvae and pupae, or adults. Some larvicides are not effective against pupae, some adulticides are ineffective against larvae.

4. Select and apply the types and formulations of pesticides that minimize non-target damage. In making a selection, a pesticide's toxicity to non-target organisms should be evaluated on a site specific basis because mosquito control pesticides present different relative hazards to a variety of non-target species. The table below illustrates this point.

Relative Field Hazard for Selected Insecticides

$\begin{array}{llll}\text { Birds } & \text { Dursban } & \text { Malathion } & \text { Baytex } \\ \text { Bees } & \text { Malathion } & \text { Baytex } & \text { Dursban } \\ \text { Fish } & \text { Baytex } & \text { Dursban } & \text { Malathion } \\ \text { Increasing Hazard } & \end{array}$


5. Properly time pesticide applications. This may reduce some hazards to a non-target species such as bees. For example Baytex and Dursban may kill bees on contact but, at mosquito control rates, they are not particularly hazardous a few hours after application.

6. Select and use insecticides having the lowest inherent toxicity, particularly where human exposure is likely. However, the manner of use greatly affects the hazards, and a selected material may have high inherent toxicity as a technical concentrate, but a relatively low hazard use. Observance of proper techniques, the employment of trained personnel and effective supervision are the principal factors controlling the safe use of insecticides.

7. Minimum effective amounts of any pesticide should be applied. This will reduce human exposure, reduce adverse effects to the environment and facilitate the simultaneous use of biological controls.

Insecticide resistance has not developed in mosquitoes in Montana. The figure below illustrates the susceptibility of larvae to Baytex (assuming an average water depth of 1 foot).

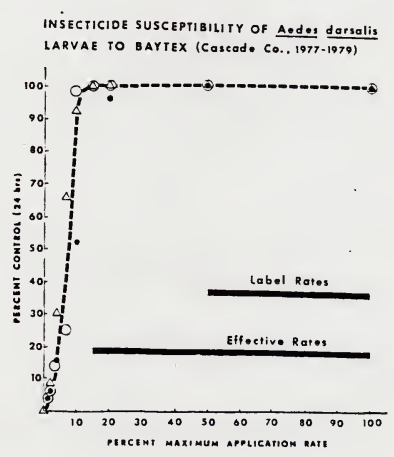

8. Treat only specific sites where mosquitoes are being produced that will cause annoyance or create an economic or a public health problem. 


\section{Information on Specific Chemicals for Mosquito Control}

The following information is given as a guideline only. The applicator must ensure that pesticides are used in strict compliance with applicable laws and regulations. Note all labels for restrictions and limitations. Mention of a proprietary product does not constitute endorsement nor does exclusion indicate disapproval.

1. Special petroleum oils.

A number of petroleum oils have been registered for control of larvae and pupae. These include Flit MLO (Mosquito Larvicide Oil), ARCO larvicide and GB1313. The toxic effect on mosquito larvae and pupae is believed to result from the oils penetration of the trachea and the resulting interference with air intake. Usual application rates are 1-3 gallons per acre or up to 5 gallons per acre in water with dense vegetation or high organic content.

Manufacturer's recommendations and precautions should be followed. Flit MLO is non-toxic to warm blooded animals and, since it is exceptionally non-phytotoxic, it can be used where ornamental and agricultural plants grow (e.g. pastures). ARCO larvicide is quite phytotoxic as well as toxic to larvae. It therefore should not be used where valuable plants might be damaged. The chief disadvantage may be cost, thus restricting general use to control pupae.

\section{Pyrethrins.}

Pyrethrum, which kills on contact, is a natural organic larvicide derived from plant materials. It is perhaps the oldest known and the safest insecticide commercially available. The usual commercial concentrate contains about $2.5 \%$ pyrethrins. A highly refined and concentrated form used for aerosol formulations contains $20 \%$ pyrethrins. The addition of a synergist, such a piperonyl butoxide increases the efficacy of pyrethrins. Emulsifiable concentrates, oil-miscible concentrate sprays and aerosols may be used to adulticide in all non-crop areas, residential areas and over any crop where adult mosquitoes occur. Pyrethrum ULV insecticide ( $5 \%$ pyrethrins $+25 \%$ piperonyl butoxide) is dispersed at 2 to $2.25 \mathrm{fl}$. oz/min at a vehicle speed of 5 $\mathrm{mph}$. The objective is to treat areas with 0.002 to 0.0025 lbs pyrethrum and 0.010 to $0.0125 \mathrm{lbs}$ of piperony 1 butoxide/acre. ivoid applying over bee hives or fields in bloom. Pyrethrum is also formulated in convenient to use tossits for control of larvae. Rates of $1 / 100$ square feet may be specified. Cost is high.

\section{Organophosphates}

(a) Abate (temephos). Abate is available as 1, 2 or $5 \%$ granules or as an emulsifiable concentrate to be 
mixed with water for use in non-crop areas. Temephos is characterized by very low toxicity to warm blooded animals ( $L D_{50}$ values to female white rates of 1300 $\mathrm{mg} / \mathrm{kg}$ oral, and more than $4000 \mathrm{mg} / \mathrm{kg}$ dermal). Its low toxicity to fish, birds mammals and other non-target organisms make it an acceptable larvicide for use in a great variety of situations. Field studies indicate no effect on rainbow trout or Gambusia at mosquito control rates. In malaria supression programs in underdeveloped countries it is used in wells and cisterns at rates of 0.5 to $1 \mathrm{ppm}$. California has specified that it not be used pastures where lactating dairy animals are being pastured.

Application rates are 0.1 to $0.5 \mathrm{lb}$. AI/acre for granular formulations. The higher rates are used in water, with high organic content or highly polluted water since abate is very labile under these conditions. When using Abate $4 \mathrm{E} \mathrm{mix}$ at $0.5-1.5$ oz/gallon water and apply at 1 gallon/acre if little emergent vegetation exists. Granular applications are more effective than liquid sprays over densely vegetated sources. Temephos is less effective as. an adulticide.

(b) Baytex (fenthion). Baytex is available as an $81 \%$ solution for dilution by oil carriers (plus an antisludge agent if held longer than a few hours); as a $46 \%$ emulsifiable concentrate (most commonly diluted with water) and as 1,2 and $5 \%$ granules. Some formulations may be used as an adulticide in residential areas, but are more commonly used as a larvicide in swamps, floodwater areas, non-crop areas, pastures and hayfieids. Some formulations indicate cattle need not be removed during application but 3 weeks must be allowed between treatments. It may be applied only once per cutting of alfalfa and up to 4 times per year on pastures. The usual rate for larviciding is $0.051 \mathrm{~b}$. AI/acre or up to $0.1 \mathrm{lb} / \mathrm{acre}$ in water of high organic content.

Fenthion inhibits blood cholinesterase, thus repeated over-exposure, may cause depression. It has a dermal toxicity rate of $313 \mathrm{mg} / \mathrm{kg}$ and an oral $\mathrm{LD}_{50}$ of 215 $\mathrm{mg} / \mathrm{kg}$. It is appreciably more toxic to bifds than to mammais. The acute oral $\mathrm{LD}_{50}$ values are $5.9 \mathrm{mg} / \mathrm{kg}, 12$ $\mathrm{mg} / \mathrm{kg}$, and $30 \mathrm{mg} / \mathrm{kg}$ to ducks, geese and chickens respectively. It is also highly toxic to bees exposed to direct treatment. On the other hand, mosquitofish and rainbow trout are not affected by the normal dosage level for larval control.

Granular formulations are favored for larviciding areas containing dense emergent vegetation or a dense growth 
of trees and shrubs. They are also less hazardous to handle than the liquid. The $2 \%$ sorptive type granules may be preferred for aerial application because they disperse before settling to the bottom. However they are lighter than the sand core type and are less likely to penetrate dense vegetation when applied by ground equipment.

Spot or residual adulticiding applications may be made by mixing emulsifiable concentrates with water at up to $2 \mathrm{oz}$. actual fenthion per gallon and applying at not more than 1 gallon finished spray per 500 square feet.

(c) Dursban (chlorpyrifos). Chlorpyrifos formulations are available as emulsifiable concentrates $1-5 \%$

granules and as a fogging concentrate ( $6 \mathrm{lb} / g a 1)$. The normal use patterns in Montana are as pre-hatch or larviciding treatments with $1 \%$ granules or $2 \mathrm{E}$ (emulsifiable). Most formulations are stable indefinitely under normal storage conditions. When applied to turf, soil and water surfaces it may be effective for several weeks, depending on the weather. Unlike many larvicides its residual effect is extended in water with a high organic content. Three to 12 week residuals have been reported in $10 \mathrm{~g}$ ponds, dairy drains, etc. Dursban may be applied to mosquito infested noncrop water areas at 0.0125 to $0.051 \mathrm{bs}$. AI/acre $(0.8$ to $3.2 \mathrm{fl}$. oz. of $2 \mathrm{E})$, depending on the vegetative cover. Pre-hatch treatments may be applied at rates up to $0.1 \mathrm{lb}$. AI/acre.

Chlorpyrifos inhibits blood cholinesterase and repeated exposure may cause a cholinesterase depression. It has $\mathrm{LD}_{50}$ values to rats of $135 \mathrm{mg} / \mathrm{kg}$ oral and $2000 \mathrm{mg} / \mathrm{kg}$ detmal. The relatively low dermal toxicity makes it one of the safer OP compounds to use. The concentrates should be handled only by persons trained in the safe use of OP compounds. Chlorpyrifos is toxic to fish and should not be used where they are valuable resources.

(d) Malathion. Malathion is available as a $91 \%$ concentrate (e.g. Cythion ULV concentrate) and as 8 1b/gallon, $55 \%$ and $57 \%$ emulsifiable concentrates for adulticiding or larviciding. Like other

organophosphates it may depress blood cholinesterase levels with repeated exposure. It is one of the safer organophosphorus compounds, having an oral $\mathrm{LD}_{50}$ values to rats of about $1000 \mathrm{mg} / \mathrm{kg}$ and a dermal $L_{50}$ over 4444 $\mathrm{mg} / \mathrm{kg}$. It is widely used in adult mosquito control and mosquito-borne disease control programs. It is the product of choice where exposure of persons, domestic animals or wildlife may occur. At usual dosage and application rates it is safe when applied in and around densely populated residential areas. Usual application 
rates of the technical concentrate applied by ULV equipment are 1-2 fl. oz/min at a speed of $5 \mathrm{mph}$ and $2-4 \mathrm{fl}$. oz/min at $10 \mathrm{mph}$. Large droplet sizes are ineffective and may damage automobile finishes. Therefore ULV equipment droplet sizes should be measured every 2 months. Application rates of 0.075 to $0.2 \mathrm{lbs} / \mathrm{acre}$ are used with ground foggers or misters.

The technical concentrate may be used as a base for making dilute sprays, or may be applied directly as a very low volume application (ULV). It can be mixed in oils for surface application as a larvicide, or for adulticidal use in thermal aerosol or mist machines. For thermal aerosol or mist blower applied aerosol adulticides, greater efficacy may result from the addition of Lethane 384 . The formula consists of $91 \%$ malathion - $3 \%$, Lethane $384-3 \%$, No 2 fuel oil or diese 1 oil - $94 \%$. The $55 \%$ to $57 \%$ malathion emulsifiable concentrates are standardized commercially available products widely used for mosquito control, agricultural and for home and garden applications.

Although malathion is an excellent larvicide, there is concern that its use in this fashion, might tend to enhance the development of resistance and negate its use thereafter as an adulticide. It is therefore suggested that it not be used routinely as a larvicide where there is a future need to use it as an

adulticide. Malathion is toxic to some species of $\mathrm{fish}$ at mosquito control rates.

4. Carbamates.

Carbamates are derivatives of carbamic acid ( $\left.\mathrm{NH}_{2} \mathrm{COOH}\right)$. They are generally poor larvicides. Baygon (propoxur) is registered with the EPA for adult mosquito control at 0.05-0.07 lb. AI/acre. The oral $L_{50}$ to rats is $86 \mathrm{mg} / \mathrm{kg}$ and the dermal $L_{50}$ is $2400 \mathrm{mg} / \mathrm{kg}$.

5. Synthetic pyrethroids.

Resmethrin (e.g. SBP-1382) formulations are available for application at. $0035 \mathrm{lb}$. AI/acre in foggers and misters and $10 \%$ SBP-1382 is available for ULV adulticiding. ULV applications are made using $2 \%$ finished formulations sprayed at $9 \mathrm{fl}$. oz per minute at a vehicle speed of $5 \mathrm{mph}$. Costs are high.

6. Insect Growth Regulators. Altosid (methoprene) is the only growth regulator currentiy registered for mosquito control. It does not kill pupae or adults. Methoprene is applied to water containing $2 \mathrm{nd}, 3 \mathrm{rd}$ and 4 th instar larvae at 0.025 to $0.05 \mathrm{lb}$. AI/acre. Three to four ounces of Altoside SR-10 (the $10 \%$ formulation) are applied in $1 / 2$ to 5 
gallons of water per acre or it is mixed with sand according to label directions and applied in this manner. It may be used in noncrop areas or pastures without removal of livestock. Sustained released briquettes containing $4 \%$ active ingredient are also available. Altosid is very safe. The technical material has an oral $\mathrm{LD}_{50}$ of greater than $34,600 \mathrm{mg} / \mathrm{kg}$ for rats and $\mathrm{LC}_{50}$ of greater than $10,000 \mathrm{ppm}$ for ducks. The $\mathrm{LC}_{5}$ for trout is $4.39 \mathrm{ppm}$. At application rates, ca. 0.009-0.85 ppm it has very little, if any, effect on mosquitofish. Cost is high. 


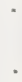


CHAPTER VI

\section{EQUIPMENT FOR GROUND APPLICATION}

\section{A. Introduction}

Information on the types of equipment available for larviciding and adulticiding is available in the American Mosquito Control Association Bulletin \#2, Ground Equipment and Insecticides for Mosquito Control, 101 pp. Only brief descriptions of the more commonly used types of equipment will be included herein. Bulletins such as A Guide for the Safe Use of Pesticides and Respiratory Protection Against Pesticides are available from the Environmental Sciences Division of the State Department of Health and Environmental Sciences.

\section{B. Types of Larviciding Equipment}

In nearly all public health insect control projects, the compressed air sprayer is standard equipment. These sprayers are small 1 to 4 (usually 2 or 3 ) gallon cylindrical tanks equipped with an air pump, hose and spray gun (wand and nozzle). After filling the tank about $3 / 4$ full, air is compressed into the remaining space to force the liquid through the nozzle. Desirable features include stainless steel construction, a pressure gauge, a large filler opening, synthetic rubber gaskets and a pressure release valve. (If no pressure release valve is present, turn the sprayer over and release pressure through the nozzle before opening). A flat fan nozzle is usually used for applying residual sprays to walls, while a hollow cone nozzle is ordinarily used for applying insecticide to vegetation and mosquito breeding sites. A stock of spare parts should be kept on hand.

Most agencies prefer hydraulic sprayers over those using compressed air tanks. The hydraulic power sprayers, with capacities of from 50 to 300 gallons (usually 50-150 gallons) can pump a maximum of from 1 to 10 gallons of spray per minute. Most which are used for mosquito control are mounted on skids or on the beds of $3 / 4$ ton trucks. This sprayer consists of a tank (usually with an agitator), a pump, a power source (the vehicle's engine or a separate gasoline engine), a pressure regulator and relief valve and one or more hoses and hand guns (and/or occasionally a boom). Hoses are usually 50 to 200 feet long. For longer length of hose it is advisable to use one with a $1 / 2$ inch interior diameter (I.D.) since there is less frictional loss of pressure than with $1 / 4$ inch or $3 / 8$ inch hose.

Two types of hand operated granule applicators are commonly used in larviciding. One is the rotary slinger plate type of grass seeder. When used in tall grass and cattails, the moving parts can get clogged unless a protective sheet of metal is mounted below and ahead of them to divert vegetation. The most common type of hand operated granulator in Montana is the "sling" seeder 
(horn seeder). This consists of a tear-drop shaped granule bag holding 5 to 15 lbs. of granules and a tapered metal tube. An applicator feeds granules into the 3 foot long tube and dispenses them through the adjustable gate by whipping the tube back and forth. While walking an applicators can throw a swath of granules from 10 to 20 feet on either side.

Power granulators are of several types. One kind commonly used is a power driven rotary plate type of seeder. Granules are fed from a hopper to a rotating plate by gravity flow and slung out in a fairly uniform swath by centrifugal force. The other type of power granulator commonly used is a modified mist blower. Granules are discharged into the air exhaust duct and moving air transports the granules to the target. Back-pack dusters can be modified in a similar manner.

\section{Types of Adulticiding Equipment}

The three types of equipment most commonly used for adult mosquito control are: 1) Ultra low volume (ULV, misting and thermal fogging).. (See Section V D, Adulticiding, for a discussion of principles governing adulticiding with each type of equipment and factors influencing their effectiveness and versatility); 2) Thermal fog generators break insecticide into aerosol sized particles by means of blasts of hot exhaust gases; and 3) Mist blowers are essentially large capacity power driven air turbines which drive air at high velocity through a tube. Several models discharge 5000 cubic feet of air per minute at 150 mph. Sprays are pumped at low pressure and volume into a discharge tube where it is atomized by a nozzle. In addition to granule hopper attachment modifications already discussed, "mini-spin" nozzles have been inserted into insecticide lines to disperse insecticide concentrates.

Ultra low volume equipment for adulticiding is of relatively recent origin. Special nozzles or attachments break insecticide concentrates up into relatively uniform particles measured in terms of microns. Advantages have already been discussed.

\section{Equipment Selection}

The equipment selected must fit the various local needs in an area. Careful survey and analysis of the extent and types of breeding areas will provide the basis for equipment selection. Power driven sprayers and granulators mounted on trucks or jeeps are suitable if an area has extensive ditches, ponds, small swamps and temporary pools which are accessible by road. If these areas are inaccessible, compressed air sprayers and hand held granulators are used. Large swamps and irrigated areas are treated with power equipment mounted on all-terrain vehicles. Where there are extensive larval populations distributed over extensive inaccessible areas, contracted spraying by air craft may be the most effective means of control. 
Other factors that are important considerations are budgetary limitations, labor costs and equipment versatility and serviceability. Equipment that can be effectively operated by one man will pay for itself in one or two seasons if compared to the labor costs of crew served equipment. A similar cost-benefit analysis can be applied to more expensive equipment that can be operated in several ways by a crew of two but which has the capability of covering the same area that 3 or 4 crews cover with more inexpensive equipment. An appropriate example may be cited for regions which have extensive sloughs (which are relatively inaccessible) and sluggish overgrown ditches. If an all terrain vehicle (ATV) were outfitted with a hydraulic sprayer and power granulator, the area becomes accessible and can be treated much more rapidly. While trailered, one could also use it to treat roadside borrow areas. 


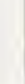




\section{CHEMICAL APPLICATION}

\section{A. Equipment Calibration}

Prior to any attempt to control mosquitoes an applicator must familiarize himself with the equipment and calibrate it. To "calibrate" is to determine the quantity of chemical that the equipment dispenses each second, minute or hour. The quantity dispensed will vary with various equipment settings (such as RPM or pressure) with various attachments (different disks and nozzles) and, in some cases, with the temperature and viscosity of the chemical. Equipment manuals which accompany the sprayers or granulators normally contain sufficient instruction for calibration and operation and are, hence, only briefly discussed.

In calibrating compressed air or hydraulic sprayers, spray into a container for an established period of time and measure the amount of material dispensed in order to determine the discharge rate/second or minute. (See also Section VIII $F(3)$, Varying the Discharge Rate.) Since the spray pattern and discharge rate vary with the pressure being used, it is advisable to calibrate and use the compressed air sprayer over a 30 to 50 psi pressure range. In this way, the average pressure will be suitable for producing the delivery rate and spray characteristics for which many nozzles are designed.

In calibrating mist blowers or thermal foggers, the tank is filled to a mark with water or fuel oil respectively. The equipment is operated for a period of time and the quantity of material necessary to replace that dispensed is measured. The discharge rate is usually measured in terms of gallons per hour. (See also Section VIII C (2), Computation of acreage for adulticiding. )

Power granulators are usually calibrated in terms of pounds of granules dispensed per minute, hour or mile of travel at a set speed. The rate of discharge selected will depend on the swath width that is obtained with the type of granule selected and the recommended dosage rate of the chemical selected. (Smaller heavier granules will give a wider swath width and the discharge rate needed will be greater). Steps to be followed are (1) measure the swath width; (2) calculate the acreage covered per mile of travel (swath width (in feet) x 5280 - 43,560); (3) multiply by lbs. of granules desired per acre (to get lbs/mile of travel); (4) multiply by the desired rate of vehicle speed (to get lbs. per hour) and (5) by trial and error adjust the flow rate of granules to meet the desired pounds/hour. (See Section VIII E (3), Dosage rates for granules and dusts for example.)

In the hand operated "sling" or horn seeders, an adjustable gate regulates the gravity flow of granules. The amount that the gate will be opened will depend on swath width and rate of travel. 
These variables will be balanced against each other as indicated in Section VIII B, Standardizing Application Rates.

Operation manuals which accompany ultra low volume (ULV) equipment should be consulted for calibration. Flow rates are again determined by swath width and the recommended dosage rates. Flow rates vary with the temperature and viscosity of the insecticide and calibrations should extend over the temperature range. The calibration of ULV equipment also includes rigorous regulation of droplet size and coverage.

\section{B. Standardizing Application Rates}

Applying the correct volume of finished spray or weight of granules is largely a matter of practice. Two approaches are used. One approach is based strictly on the time required to apply the correct quantity to a given area. One can develop a table that will show the number of seconds required to dispense required volumes or weights over a series of areas. The other approach is based on the development of a particular constant rate of movement by the applicator, nozzle or equipment. The rate of movement or the time that chemical is actually being dispensed is dependent upon the discharge rate of the equipment (in turn determined by nozzle type, pressure, etc.).

In developing the appropriate rate of movement; measure and stake out a test area and use one of the following approaches (1) fill the equipment to a certain mark, (2) spray the test area uniformly, (3) measure the amount of material required to fill the equipment to the original level, (4) compare with the amount of material which should have been used and (5) adjust the rate of application accordingly. Or, (1) place only the volume or weight of material required for treatment in the equipment, (2) spray or granulate the test area and (3) try to adjust the rate of travel/application so that the chemical runs out just as the area has been completely and uniformly covered (i.e.just as the applicator reaches the stake at the other end of a inear area or returns to the starting stake in a more circular or rectangular area).

\section{Computation of Acreage}

Since insecticide labels usually express the limits for dosage rates as pounds or fluid ounces of active ingredients per acre, it is necessary to calculate the acreage of each site to be treated. Methods used to compute acreage are given below.

1. Computation of acreage for larviciding.

In smaller areas, the acreage may be estimated by pacing off the length and width of the area to be treated. If the area is relatively square or rectangular, a multiplication of length $x$ width will give the area in square yards. (Although the average "normal" step is about 30 inches, one 
can develop a step of about 36 inches with 1ittle practice.) If the area is more triangular in shape than rectangular, the length $x$ width value should be divided by 2 . It is then necessary to convert square yard measurements to acres. This may be done by dividing the number of square yards by 4840 ( 1 acre $=4840$ square yards $=43,560$ square feet). It is more convenient, less time consuming and there is less chance for mathematical error if a table such as below is consulted.

$\begin{array}{cccc}\text { Square Yards } & \text { Acres } & \text { Square Yards } & \text { Acres } \\ 25 & .0052 & 650 & .1343 \\ 50 & .0103 & 700 & .1446 \\ 100 & .0206 & 750 & .1570 \\ 150 & .0309 & 800 & .1653 \\ 200 & .0413 & 850 & .1756 \\ 250 & .0537 & 900 & .1858 \\ 300 & .0619 & 950 & .1962 \\ 350 & .0723 & 1000 & .2066 \\ 400 & .0826 & 2000 & .4132 \\ 450 & .0929 & 3000 & .6198 \\ 500 & .1033 & .8264 \\ 550 & .1157 & 4000 & 1.0330 \\ 600 & .1239 & 5000 & \end{array}$

Additional columns can be added to the table to further reduce the chances for error and save time. One can e.g. calculate the gallons or pounds of actual and mixed chemical required for each area involved and/or the number of seconds the trigger valve would have to be open to deliver the required amount of chemical.

It is suggested that a conversion table be maintained in the spray vehicles. It is further suggested that the acreage at each mosquito source be recorded. Although the acreage at each site may vary from season to season and time to time, some ponds have rather stable boundaries and some areas flooded to about the same extent with each irrigation.

For larger areas or for long ditches or borrow pits, the acreage may be more rapidly estimated by the simple field calculation noted in Formula 1 below. This is based upon a figure of an 8 foot swath width for one mile of travel.

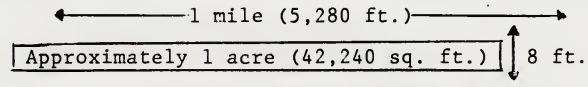

Formula 1 Acreage Treated $=\frac{\text { mileage covered } x \text { swath width }}{8}$ 
Example 1. Calculate the acreage treated by larviciding an area $1 / 2$ mile long and 12 feet wide.

$$
\text { Acreage Treated }=\frac{0.5 \times 12}{8}=.75 \text { acres }
$$

\section{Computation of acreage for adulticiding}

In space treatments (misting and fogging) the acreage treated is a variable figure dependent upon the swath width taken. The first step then is to determine the swath width. This may be done by setting out cages of mosquitoes and adulticiding; using visual observations of a fog; or setting out strips of paper and spraying a dye solution (minus insecticide). While this may be practical in calibrating a machine, an operator would not find it practical to conduct such tests routinely. As a practical consideration, the swath widths in urban areas are usually taken as the length or width of the city block. The approximate acreage treated by space application of insecticides may be determined by Formula 1 above.

Example 2. Calculate the acreage treated by a mister traveling 4 miles where the swath width is 200 feet.

$$
\text { Acreage }{ }_{8} \text { Treated }=4 \times 200=100 \text { acres }
$$

\section{Formulation Dilution}

Insecticides for mosquito control are sold in Montana in a number of formulations which have already been discussed. Many require dilution.

Pesticide container labels give directions for dilution prior to use. The level of dilution which you use should fall within the limits specified on the label. However, other factors need consideration: (1) the more concentrated the finished spray is, the more closely the application rate must be controlled. Slightly over or under spraying of a more dilute solution has less effect on the amount of active ingredient applied than slightly over or under spraying a more concentrated solution; the more carrier (oil or water) used, the less finished spray that can be held in the spray tank; and (3) the more carrier used, the higher the carrier cost.

The actual dilutions used will be based upon the equipment characteristics (discharge rate) and the rate of application. If the equipment puts out a large volume in a short period of time, the finished spray may be more dilute or the rate of application very fast. 


\section{E. Determining Amount of Mixed Chemical Needed}

After determining the size of the area needing treatment (in acres), one can determine the amount of finished spray needed. This will depend on: (1) the allowable dosage rate (defined as the amount of pesticide applied to a given area-usually pounds or fluid ounces of active ingredient per acre) specified on the insecticide label and (2) the degree to which the insecticide concentrate has been diluted. The following formula may be used to determine the quantity of insecticide needed.

Formula 2. Gallons finished $=$ Dosage rate $x$ acreage treated

spray needed Insecticide (lbs or $f 1 \mathrm{oz}$ )/gal. finished spray

Example 3. A dosage rate of $0.06 \mathrm{lbs}$. of fenthion/acre is desired on 4 acres of standing water in a field. The finished spray contains 0.08 lbs. of active ingredient per gallon. (To obtain this, one could mix e.g. 2 gallons of Baytex 4 EC (4 lb/gal) with 98 gallons of water.) How much finished spray should be used? By Formula 2:

Gallons needed $=\frac{0.06 \times 4}{0.08}=3$ gallons

Formulas 3 and 4 below may be revised to determine the gallons of liquid insecticide needed (given percent concentration or specific gravity) or pounds of insecticide granules needed respectively.

F. Computation of Dosage Rates.

After determining the acreage treated and amount of insecticide used, one can establish that the correct dosage rate was used. Remember, the rates applied must fall within the limits specified on the insecticide label.

1. Dosage rates for liquid formulations given pounds active ingredient/galion in the finished spray may be calculated by the following revision of Formula 2:

Dosage Rate $=\frac{\text { Gallons applied } x \text { insecticide/gallon (1bs) }}{\text { Acreage treated }}$

Example 4. An area 2 miles long and 200 feet in depth was treated with 40 gallons of fenthion emulsion containing 0.08 lbs of active ingredient/gallon. Calculate the dosage rate.

Using Formula 1: Acreage treated $=\frac{2 \times 200}{8}=50$ acres

Using Formula 2: Dosage rate $=\frac{40 \times 0.08}{50}=0.064 \mathrm{lbs} /$ acre 
2. Dosage rates for liquid formulations (given various percentages).

The strengths of liquid concentrates are often given as percentage of active ingredient rather than in pounds/gallon. Occasionally the specific gravity of the concentrate is given. The following formula may be used.

Formula 3

a. Dosage rate $=\frac{\text { gallons applied } \times \mathrm{wt} / \mathrm{gal} \text { of formulation } \mathrm{x} \% \text { conc }}{\text { acreage treated }}$ or (where given specific gravity)

b. Dosage rate $=\frac{\text { gallons applied } \times \mathrm{sp} \cdot \mathrm{gr} \cdot \times 9.345 \times \% \text { conc }}{\text { acreage treated }}$

3. Dosage rates for granules and dusts may be calculated by:

Formula 4 Dosage rate $=\frac{\text { Pounds applied } x \% \text { of concentration }}{\text { acreage treated }}$

Example 5. A $2 \%$ fenthion granular formulation is used for larviciding a swampy wasteland area which is 1 mile long. The swath width is 16 feet. The rate of application is $20 \mathrm{lbs} / \mathrm{mile}$ of travel ( $100 \mathrm{lbs} /$ hour at $5 \mathrm{mph}$ ). Calculate the dosage rate.

Using Formula 1: Acreage treated $=\frac{1 \times 16}{8}=2$ acres

Using Formula 4: Dosage Rate $=\frac{20 \times 0.02}{2}=.2 \mathrm{lbs} /$ acre

G. Methods of Varying the Dosage Rate

There are generally three methods used to vary the dosage rate: (1) varying the formulation strength; (2) varying speed of travel; and (3) varying the discharge rate. Most often in space treatment, the simplest and most practical method is to use a more or less concentrated formulation. In this way, it is possible to maintain the cptimum speed of travel ( $5 \mathrm{mph}$ ) and the standard discharge rate $\mathrm{g}$ iving the best droplet size and coverage. In larviciding, it may be practical to vary the formulation strength for iff ferent larger jobs where the terrain may dictate different iverage speeds. There may be several reasons for wishing to vary the speed of travel. Heavy vegetation at a particular larval station may require a higher dosage rate; the physical situation may require that a different swath width be taken, etc. In some situations, it may be more practical to vary the discharge rate. The terrain may be such that the speed of travel has to be temporarily reduced or such that the speed of travel could be more rapid than normal. 


\section{Adjusting formulation strength}

If one wished to maintain a standard discharge rate (e.g. $100 \mathrm{gal} / \mathrm{hr}$ ) and standard speed (e.g. $5 \mathrm{mph}$ ) over the same swath width, one could vary the dosage rate by varying the dilution of insecticide concentrate. One can determine the formulation strength needed to obtain a given dosage rate by the following rearrangement of Formula 2:

$\frac{\text { Insecticide (lbs) }}{\text { gal. finished spray }}=\frac{\text { (Dosage rate) (acres treated) }}{\text { gallons applied }}$

Example 6. You wish to reduce the dosage rate in example 4 from $0.064 \mathrm{lbs} / \mathrm{acre}$ to $0.05 \mathrm{lbs} / \mathrm{acre}$ and still maintain a discharge rate of $20 \mathrm{gal} / \mathrm{mile}$ where, due to a 200 foot swath width, 25 acres were covered each mile. Compute the gallons of $4 \mathrm{ib} / \mathrm{gal}$ concentrate needed to make 100 gallons of finished spray. Using the above formula:

$\frac{\text { Insecticide (lbs) }}{\text { gal. finished spray }}=\frac{0.05 \times 25}{20}=0.0625 \mathrm{lb} / \mathrm{gal}=6.251 \mathrm{~b} / 100 \mathrm{gal}$.

Thus one would have to use 1.56 gallons of concentrate containing 4 lbs of active ingredient per gallon to get the 6.25 lbs per 100 gallons desired in the finished formulation. (This would amount to using 25 pints of concentrate and diluting it to 100 gallons -- determined as: $1.56 \mathrm{gal} \times 16 \mathrm{pints} / \mathrm{gal}=24.96 \mathrm{pints.)}$ NOTE: For a different dilution swath width, discharge rate, vehicle speed or dosage rate, a different dilution would be appropriate.

2. Varying the speed of travel

Doubling the rate of travel doubles the acreage treated and halves the dosage rate if other variables are maintained. Conversely any decrease in speed would result in a proportionate increase in the dosage rate. From the formulation strength, discharge rate and desired dosage rate, one can compute the needed vehicle speed for any given swath width. By rearranging Formula 2, one can obtain the gallons of finished spray needed per acre. By dividing the discharge rate ( $\mathrm{gal} / \mathrm{hr}$ ) by gallons per acre applied, one obtains the number of acres which need to be covered per hour. One can then consult the coverage rate table below to determine the appropriate rate of speed (modified from the Depts. of Air Force, Army and Navy Insect and Rodent Control Manual and the Cascade County Mosquito Abatement District Manua l).

Example 7. A mister delivers $100 \mathrm{gal} / \mathrm{hr}$ of a formulation containing $0.0625 \mathrm{lb} / \mathrm{gal}$. The operator desires a dosage rate of $0.05 \mathrm{lbs} / \mathrm{acre}$ over a $200 \mathrm{ft}$. swath width. Calculate the appropriate vehicle speed. By substituting in a modification of Formula 2, one obtains: 


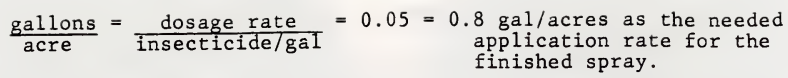

The acreage treated/hr at a discharge rate of $100 \mathrm{gal} / \mathrm{hr}=$

$$
\frac{100 \mathrm{gal} / \mathrm{hr}}{0.08 \mathrm{gal} / \mathrm{acre}}=125 \mathrm{acres} / \mathrm{hr}
$$

From the following table, one can observe that, where the swath width is 200 feet, the appropriate speed is about $5 \mathrm{mph}$.

Rate of Coverage for Given Rates of Travel and Given Swath Widths

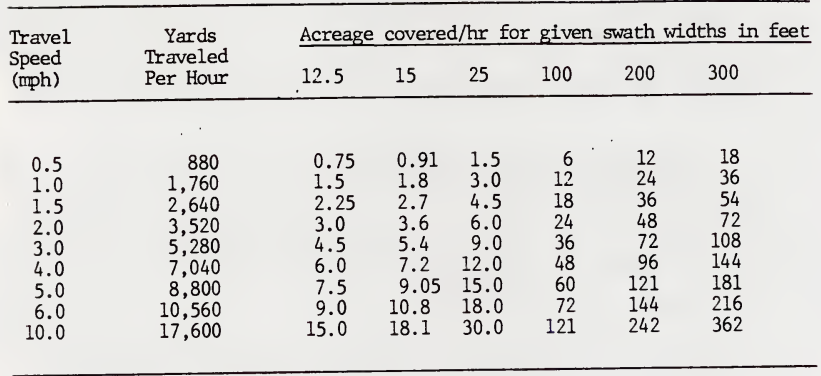

In the absence of a table or with a different swath width, one could estimate the appropriate speed of travel by the following modification of Formula I:

Speed $(\mathrm{mph})=\frac{\text { Acres treated } / \mathrm{hr} \times 8 \mathrm{ft}}{\text { swath width (ft.) }}$

In example 7: Speed $=\frac{125 \times 8}{200}=5 \mathrm{mph}$

If one knows the dosage rate resulting from a particular speed of travel, he can apply any other dosage rate over the same area by changing the speed of travel. Since speed is inversely proportional to the dosage rate, one can set up a simple ratio:

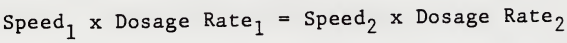


Example 8. A $57 \%$ Malathion EC (5 1b/gal) is to be misted over an irrigated alfalfa field adjacent to town. The field is treated because it contains residual larval pools and affored adults extensive cover. The formulation strength and discharge rate were such that a dosage rate of 0.2 lbs/acre was delivered in town at $10 \mathrm{mph}$. The operator wished to apply $0.51 \mathrm{bs} / \mathrm{acre}$ over the field. Compute the appropriate speed.

$$
\begin{aligned}
& 0.2 \times 10=0.5 \times \text { Speed }_{2} \\
& \text { Speed }_{2}=\frac{.2 \times 10}{.5}=4 \mathrm{mph}
\end{aligned}
$$

3. Varying the discharge rate

This method of varying the dosage rate is most often used while larviciding. In discharging liquid formulations, the dosage rate may be varied by changing the spraying pressure or nozzle tips or disks. Increasing the spraying pressure has the disadvantage of decreasing the droplet size and consequently increasing the potential drift of the insecticide. A change in pressure does not result in a proportionate change in the discharge rate. (The table below illustrates this.) Larger changes in the discharge rate are more effectively brought about by changing the nozzle tips. The following table (taken from the Cascade County Mosquito Abatement District Manual) illustrates the discharge rate that various nozzle sizes emit at various pressures.

Data for Trigger-Valve Hand Guns

Rate (gal/min)

\begin{tabular}{lcccc} 
Nozzle & 200 psi & 300 psi & 400 psi & 500 psi \\
\hline D -4 & 1.2 & 1.5 & 1.6 & 1.9 \\
D-5 & 1.8 & 2.2 & 2.6 & 2.8 \\
D-6 & 2.5 & 3.0 & 3.4 & 3.8 \\
D-7 & 3.3 & 4.0 & 4.4 & 4.9 \\
D-8 & 4.3 & 5.2 & 6.0 & 6.6
\end{tabular}




\section{APPENDIX}

Lineal Measure (Length):

1 inch (in) $=2.54$ centimeters $=25.4$ millimeters $=$ 25,400 microns

1 foot $(\mathrm{ft}) \quad=12$ inches $=30.48$ centimeters $=$ 0.3048 meter

1 yard $(\mathrm{yd})=3$ feet $=0.9144$ meter

$1 \mathrm{mile}(\mathrm{mi})=160$ rods $=1,760$ yards $=5,280$ feet $=$ 1.6094 kilometers

1 micron $(M)=0.001$ millimeter $=0.00004$ inch $(1 / 25,400)$

1 millimeter $=0.0394$ inch

1 centimeter $=10$ millimeters $=0.3937$ inch

1 meter $\quad=100$ centimeters $=3.281$ feet $=$ 39.37 inches

$1 \mathrm{kilometer}=1,000$ meters $=0.6214 \mathrm{miles}=$ 3,281 feet

Square Measure (area):

1 square inch $=6.45$ square centimeters

1 square foot $=144$ square inches $=0.0929$ square meter $=929$ square centimeters

1 square yard $=9$ square feet $=0.8361$ meter

1 acre

$=43,560$ square feet $=4,840$ square yards $=160$ square rods $=0.4047$ hectare

1 square mile $=640$ acres $=259$ hectares

1 square meter $=1,550$ square inches $=10.764$ square feet

1 hectare $\quad=2.471$ acres $=10,000$ square meters

1 square kilometer $\quad=0.3861$ square mile 


\section{Volume or Capacity Measure (Cubic):}

1 cubic inch $=16.387$ cubic centimeters

1 cubic foot $=1,728$ cubic inches $=29.922$ U.S. 1iquid quarts $=28.316$ liters $=0.80357$ U.S. bushel

1 cubic yard $=27$ cubic foot $=0.7646$ cubic meter

1 cubic centimeter $=0.001$ cubic decimeter $=0.061$ cubic inch

1 cubic meter $=35.31$ cubic feet $=1.308$ cubic yard $=$ 264.2 gallons

\section{Volume or Capacity Measure (Liquid):}

1 fluid ounce

(U.S.) $=2$ tablespoonfuls $=29.57$ milliliters

1 cupful $=8$ fluid ounces

1 pint (pt) = 2 cupfuls $=16$ fluid ounces $=0.4732$ liter

1 quart (qt)

(U.S.) $=2$ pints $=0.9463$ liter

1 gallon $(\mathrm{gal})=4$ quarts $=0.8333$ gallon (Imperial or (U.S.) British) $=3.785$ liters $=0.1337$ cubic foot

1 liter $\quad=1,000$ milliliters $=1.057$ quart $=0.2642$ gallon

Weight:

1 grain $(\mathrm{gr})=64.7989$ milligrams

1 ounce (oz)

(avoirdupois $)=437.5$ grains $=28.3495$ grams

1 pound (lb)

$($ avoirdupois $)=16$ ounces $=7,000$ grains $=453.59$ grams

1 ton

(U.S. short) $=?, 000$ pounds $=907.185$ kilograms

1 ton

(U.S. long) $=2,240$ pounds $=1,016.047$ kilograms

1 microgram $=1$ gamma -0.001 milligram (mg) 
1 gram $(\mathrm{gm})=1,000$ milligrams -15.432 grains $=$ 0.03527 ounce

1 kilogram $(\mathrm{kg})=1,000$ grams -2.205 pounds

1 ton $($ metric $)=1,000$ kilograms $-2,204$ pounds

At all temperatures up to 100 degrees $F$, one gallon of water weighs approximately 8.3 pounds.

\section{Temperature conversion:}

To convert degrees Centigrade to degrees Fahrenheit, multiply by $9 / 5$ and add 32 .

To convert degrees Fahrenheit to degrees Centigrade, subtract 32 and multiply by $5 / 9$.

$\underset{\mathrm{C}}{\text { degrees }}=\underset{\mathrm{F}}{\text { degrees }} \underset{\mathrm{C}}{\text { degrees }}=\underset{\mathrm{F}}{\text { degrees }} \underset{\mathrm{C}}{\text { degrees }}=\underset{\mathrm{F}}{\text { degrees }}$

\begin{tabular}{rrrrrr}
\hline-40 & -40.0 & 0 & 32.0 & 40 & 104.0 \\
-35 & -31.0 & +5 & 41.0 & 45 & 113.0 \\
-30 & -22.0 & 10 & 50.0 & 50 & 122.0 \\
-25 & -13.0 & 15 & 59.0 & 55 & 131.0 \\
-20 & -4.0 & 20 & 68.0 & 60 & 140.0 \\
-15 & +5.0 & 25 & 77.0 & 80 & 176.0 \\
-10 & 14.0 & 30 & 86.0 & 100 & 212.0 \\
-5 & 23.0 & 35 & 95.0 & & \\
\hline
\end{tabular}

In calculating intermediate values, 1 degrees $\mathrm{C}=1.80$ degrees $\mathrm{F}$, and 1 degree $F=0.56$ degrees $C$.

\section{CALCULATING CAPACITY OF SPRAYER TANKS}

The capacity of tanks of hand or power sprayers in gallons can be calculated as follows:

Cylindrical tanks (circular cross sections): Multiply length in inches by square of diameter in inches, multiply the product by 0.0034 .

Tanks with elliptical cross section: Multiply length in inches by short diameter in inches by long diameter in inches; multiply the product by 0.0034 .

Rectangular tanks (square or oblong cross section): Multiply length by width by depth all in inches; multiply product by 0.004329 . 


\section{CONVERSION RATE}

$\underline{\text { Pounds per Acre } / \text { Foot of Water }=\text { Parts per Million }}$

1 Acre $=43,560$ Square Feet

1 Acre Foot $=43,560$ Cubic Feet

1 Cubic Foot of Water $=7.481$ Gallons

1 Gallon of Water $=8.337$ Pounds

1 Acre Foot of Water Weighs $2,726,797.865$ Pounds

$\begin{array}{ccr}\begin{array}{c}\text { Toxicant } \\ \text { (pounds/acre) }\end{array} & \begin{array}{c}\text { Parts Per } \\ \text { Milion (mg/kg) }\end{array} & \begin{array}{r}\text { Parts P } \\ \text { Billio }\end{array} \\ 5.45 & 2.0 & \\ 2.73 & 1.0 & 2000 \\ 2.46 & .9 & 1000 \\ 2.18 & .8 & 900 \\ 1.91 & .7 & 800 \\ 1.64 & .6 & 700 \\ 1.37 & .5 & 600 \\ 1.10 & .4 & 500 \\ .82 & .3 & 400 \\ .55 & .2 & 300 \\ .28 & .1 & 200 \\ .24 & .09 & 100 \\ .21 & .08 & 90 \\ .19 & .07 & 80 \\ .16 & .06 & 70 \\ .13 & .05 & 60 \\ .10 & .04 & 50 \\ .082 & .03 & 40 \\ .055 & .02 & 30 \\ .027 & .01 & 20 \\ .024 & .009 & 10 \\ .021 & .008 & 9 \\ .019 & .007 & 7 \\ .016 & .006 & 6 \\ .013 & .005 & 5 \\ .010 & .004 & 4\end{array}$




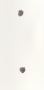




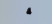


